\title{
Inovações frugais em empreendimentos sociais de serviços financeiros em Fortaleza e região Metropolitana
}

\section{Frugal innovations in social financial services ventures in Fortaleza and the metropolitan area}

\author{
Ezequiel Alves Lobo Mestre em Administração. Universidade Estadual do Ceará (UECE) - Brasil. \\ https://orcid.org/0000-0003-4004-3470 \\ Ana Cristina Batista dos Santos \\ https://orcid.org/0000-0001-8838-6937 \\ José Iran Batista de Melo Filho \\ https://orcid.org/0000-0002-8091-2311 \\ Brenno Buarque \\ https://orcid.org/0000-0001-6656-9759 \\ Domingos Albano Matos de Menezes \\ https://orcid.org/0000-0002-1996-5211 \\ ezequiellob02013@gmail.com \\ Doutora em Administração. Universidade Estadual do Ceará (UECE) - Brasil. \\ ana.batista@uece.br \\ Mestre em Administração. Universidade Estadual do Ceará (UECE) - Brasil. \\ irandemelo.idm@gmail.com \\ Doutorando em Administração. Universidade Estadual do Ceará (UECE) - Brasil. \\ brenno_buarque@hotmail.com \\ Mestre em Administração. Universidade Estadual do Ceará (UECE) - Brasil. \\ jrnumeral@gmail.com
}

\section{RESUMO}

Este estudo tem como objetivo compreender o processo de inovações frugais em empreendimentos sociais de serviços financeiros na região metropolitana de Fortaleza. Foi utilizada a técnica de entrevista para coleta dos dados, que foram analisados por meio de análise temática de conteúdo. Após a análise das narrativas emergiram quatro temas que foram dominantes nas entrevistas: história, propósito e objetivo, inovação e inclusão social e dificuldades. Foram identificadas as inovações frugais presentes nos empreendimentos sociais e o seu processo, sendo possível visualizar a situação das comunidades beneficiadas antes e depois dessas inovações. Além disso, foi observado que a perspectiva de inovação presente nos empreendimentos sociais está baseada na inclusão social.

Palavras-chave: Inovação frugal. Serviços financeiros. Empreendimentos sociais.

\begin{abstract}
This study aims to understand the process of frugal innovations in social enterprises of financial services in the metropolitan region of Fortaleza. The interview technique was used to collect the data, which were analyzed through thematic content analysis. After analyzing the narratives, four themes emerged that were dominant in the interviews: history, purpose and objective, Innovation and social inclusion and difficulties. The frugal innovations present in the social enterprises and their process were identified, being possible to visualize the situation of the benefited communities before and after these innovations. In addition, it was observed that the perspective of innovation present in social enterprises is based on social inclusion.
\end{abstract}

Keywords: Frugal innovation. Financial services. Social enterprises.

Recebido em 10/10/2020. Aprovado em 05/11/2020. Avaliado pelo sistema double blind peer review. Publicado conforme normas da ABNT. https://doi.org/10.22279/navus.2021.v11.p01-13.1442 


\section{INTRODUÇÃO}

A desigualdade no contexto econômico atual contribui para que cada vez mais um número maior de pessoas careça de assistência em muitas necessidades básicas, tais como: educação, moradia, saúde (FISCHER; COMINI, 2012; GENU et al., 2017). Com o aumento constante dessas demandas, as questões sociais deixam de fazer parte somente de agendas políticas e passam a ser consideradas também em estudos acadêmicos se tornando um desafio comum para sociedade e governantes (OLIVEIRA, 2004; GENU et al., 2017)

Diante de grandes diferenças sociais e econômicas, as práticas inovadoras surgem como alternativa para minimizar e em alguns casos até solucionar questões sociais. Nesse contexto, os empreendimentos sociais têm assumido um papel de grande relevância pois têm como objetivo realizar transformações sociais e trabalhar no sentido de proporcionar uma melhor qualidade de vida às pessoas (ASHOKA, 2018).

Os empreendimentos sociais, conforme Rosolen, Tiscoski e Comini (2014), criam valor social e introduzem serviços e produtos que geram transformação na sociedade. Assim atuam em diversos setores econômicos, tais como: saúde, educação, causas jurídicas e serviços financeiros, que é o caso do estudo em questão. O foco está em atender aqueles que fazem parte da base da pirâmide social, os mais pobres.

De forma semelhante, a inovação frugal surge com o objetivo de trazer soluções simples e acessíveis financeiramente para atender as necessidades do público de baixa renda ou comunidades especificas, considerando que os produtos e serviços frugais são mais baratos, mas mantém as funcionalidades (LELIVELD; KNORRINGA, 2017)

Nessa perspectiva, são estreitas as relações entre empreendedorismo social e inovação frugal tendo em vista que os dois possuem como objetivo atender as necessidades daqueles que compõem a base da pirâmide. Conforme colocam Pervez, Maritz e Waal (2013), as inovações surgem como uma proposta para criação de negócios sociais e inclusão.

No entanto, existe uma carência de pesquisas que se proponham a explorar a relação entre inovação frugal e empreendedorismo social, tendo em vista que os estudos sobre inovação frugal estão mais focados em verificar o estado da arte (LELIVELD; KNORRINGA, 2017; PISONI; MICHELINI; MARTIGNONI, 2017), realizar aplicações em estudos de casos (BIANCHI, et al., 2017; WINTERHALTER, et al., 2017; MELKAS; OIKARINEN; PEKKARINEN, 2018) e estudar a relação entre inovação frugal e economias emergentes (ALTMANN; ENGBERG, 2016; HYYPIA; KHAN, 2018).

Dessa forma, a importância do estudo se dá devido a busca da compreensão de como as inovações frugais estão presentes nos empreendimentos sociais desenvolvendo uma relação ainda não proposta na academia e reforçando o importante papel que as inovações frugais e os empreendimentos sociais desempenham na sociedade atendendo as necessidades da classe de baixa renda. Assim como, oportuniza que o estado da arte a respeito da inovação frugal seja recapitulado com a proposição de uma nova abordagem.

A partir dessa conjuntura, elegeu-se como objeto de estudo a inovação frugal no contexto de empreendimentos sociais, com o questionamento de como ocorre o processo de concepção e desenvolvimento da inovação frugal em um tipo organizacional também peculiar, os empreendimentos sociais? Neste sentido, objetivo geral é compreender o processo de inovação frugal em empreendimentos sociais de serviços financeiros.

Para isso, foi a adotada uma abordagem qualitativa, pois busca compreender em profundidade um fenômeno social em um determinado contexto (MINAYO, 2013). Classifica-se como exploratória e descritiva, pois busca descrever como ocorrem os processos de inovação frugal em empreendimentos sociais de fins financeiros (VERGARA, 1998). Para a coleta dos dados primários utilizou-se de entrevistas em profundidade que foram transcritas e analisadas por meio da análise de conteúdo (BARDIN, 1977).

\section{EMPREENDEDORISMO SOCIAL}

O conceito de empreendedorismo tem sido utilizado de forma muito ampla na literatura devido a sua aplicação em diversas áreas. Segundo Rosolen, Tiscoski e Comini (2014), a grande diversidade da aplicação do termo pode ser justificada pela variedade de realidades em que os empreendimentos sociais surgem levando 
em consideração aspectos econômicos, políticos e sociais de cada contexto onde o empreendimento está inserido.

Nesta pesquisa, é adotada a definição de Peredo e Mclean (2006) que consideram que o empreendedorismo social: "abrange as atividades e os processos realizados para descobrir e explorar oportunidades, a fim de aumentar a riqueza social, criando novos empreendimentos e os gerenciando de maneira inovadora". Nesse sentido os autores consideram que os empreendedores sociais enxergam necessidades e buscam supri-las sempre realizando mudanças que tragam bem-estar para a sociedade.

Pervez, Maritz e Waal (2013) destacam a importância dos empreendimentos sociais em atender as necessidades das pessoas que fazem parte da base da pirâmide, pois carecerem de assistência em muitos aspectos sociais tais como: moradia, saúde e educação. Corroborando este aspecto, Tan, Williams e Tan (2005) colocam que o empreendedorismo social é voltado para atender as necessidades dos mais pobres.

Nessa perspectiva, Braga (2013) considera que os empreendedores sociais têm como objetivo gerar mudanças na comunidade onde estão inseridos buscando sempre soluções inovadoras nas diversas esferas da sociedade. Os empreendedores convencionais, por sua vez, têm como foco o lucro do sócio e atender às necessidades dos seus clientes. Melo Neto e Froes (2002) também ressaltam diferenças entre o empreendedorismo empresarial e o empreendedorismo social. Conforme pode ser visto no quadro abaixo:

Quadro 1 - Aspectos do empreendedorismo empresarial e empreendedorismo social

\begin{tabular}{|l|l|}
\hline Empreendedorismo Empresarial & Empreendedorismo Social \\
\hline 1.É individual & 1.É coletivo \\
\hline 2. Produz bens e serviços para o mercado & 2. Produz bens e serviços à comunidade \\
\hline 3. Tem o foco no Mercado & $\begin{array}{l}\text { 3. Tem o foco na busca de soluções para os } \\
\text { problemas sociais }\end{array}$ \\
\hline 4. Sua medida de desempenho é o lucro & 4. Sua medida de desempenho é o impacto social \\
\hline $\begin{array}{l}\text { 5. Visa a satisfazer as necessidades dos } \\
\text { clientes e a ampliar as potencialidades } \\
\text { do negócio }\end{array}$ & $\begin{array}{l}\text { 5. Visa resgatar pessoas da situação de risco social } \\
\text { e promovê-las. }\end{array}$ \\
\hline
\end{tabular}

Fonte: Melo Neto; Froes (2002, p.11).

Conforme observado no Quadro 1, fica claro que o interesse do empreendedor empresarial concerne ao favorecimento do seu negócio visando o lucro individual. Enquanto o empreendedor social tem como foco o coletivo que vai beneficiar a comunidade e trazer soluções para os problemas sociais. É importante ressaltar o fato de que um empreendimento ser social não significa que ele não vise o lucro para sua própria subsistência (DACIN; DACIN; TRACEY, 2011).

Apesar da importante função que os empreendimentos sociais desempenham na sociedade são muitos os problemas que enfrentam. Dentre os quais, o principal é a restrição de recursos que restringe os empreendimentos sociais de avançar em muitas melhorias principalmente quando estão em fase inicial (ONOZATO; TEIXEIRA, 2013).

\section{INOVAÇÃO FRUGAL}

Em um contexto social no qual as demandas dos menos favorecidos são cada vez maiores, à medida que estes possuem maior acesso a determinados produtos e serviços, também surge uma nova forma de atender às necessidades dos consumidores da base da pirâmide, e possibilitar a inclusão social. Nesse sentido, Prahalad $(2005$, p. 10) considera que envolve "ajudar a população de baixa renda a melhorar sua qualidade de vida, produzindo e distribuindo produtos/serviços que estejam de acordo com os padrões culturais de cada local e que sejam, ao mesmo tempo [...] economicamente rentáveis." 
Esse cenário de grandes demandas é mais presente em economias emergentes que são caracterizadas por uma alta taxa de crescimento populacional e consequentemente maior número de consumidores. O que exige soluções inovadoras e que estejam adaptadas à realidade do público de baixa renda que somam a grande maioria. Com a intenção de explicar o fato de economias industrializadas estarem em países emergentes surgem diversas teorias como inovação de baixo custo, inovação reversa, inovação disruptiva, inovação frugal que em países como a Índia é chamada de jugaad (BHATTI; VENTRESCA, 2013).

Das perspectivas de inovação apresentadas, o conceito de inovação frugal é o que está relacionado a soluções simples e de baixo custo que são pensadas dentro de uma realidade de restrições ou como o próprio significado de frugal é colocado como "pouco gasto", "uso econômico" ou "viver sem desperdício" (PISONI; MICHELINI; MARTIGNONI, 2017).

Em uma recente contribuição sobre a definição de inovação frugal Pisoni, Michelini e Martignoni (2017), consideram que a inovação frugal tem sido definida de muitas maneiras e apresentam três gerações quanto à evolução do conceito. A primeira geração foi descrita como sendo orientada para o produto, pois destaca características dos produtos e serviços frugais. A segunda, apresenta um conjunto de variáveis que indicam as diferenças entre as várias formas de restrição de recursos e a terceira identificou três critérios que caracterizam uma inovação frugal: redução substancial de custos, concentração em funcionalidades básicas e desempenho otimizado.

Conforme apontam Radjou, Prabhu e Ahuja (2012), o princípio básico da inovação frugal é fazer mais com menos e fazer melhor com menos. Nesse sentido Bathi (2012) coloca que as inovações frugais são diferenciadas dos outros tipos de inovações devido alavancar a capacidade empreendedora e gerar a possibilidade de abertura de novos negócios.

Nessa orientação, é importante ressaltar que a inovação é apresentada como uma proposta socialmente responsável. Desse modo, a inovação frugal está presente na academia sobre a perspectiva de negócios sociais ou capitalismo inclusivo que aborda as questões de como ter lucro e objetivos sociais (PERVEZ; MARITZ; WAAL, 2013). Dessa forma, a inovação frugal pode ser utilizada como uma ferramenta para o empreendedorismo social tendo em vista os dois constructos terem como foco atender a base da pirâmide social.

Desse modo, é possível observar a relação entre o empreendedorismo social e a inovação frugal, onde ambos buscam atender as demandas da base da pirâmide (MELO NETO; FROES, 2002; PRAHALAD, 2005; TAN; WILLIAMS; TAN, 2005; PERVEZ; MARITZ; WAAL, 2013) o que pode ocasionar ao empreendedor social a restrição de recursos financeiros e é solucionado por meio da inovação frugal que se utiliza de matérias-primas simples e faz um uso racional dos recursos procurando otimizar o serviço ou produto (ONOZATO TEXEIRA, 2013; PISONI; MICHELINI; MARTIGNONI, 2017) tornando possível a exploração das oportunidades na base da pirâmide alavancando a capacidade empreendedora de gerar novos negócios (PEREDO; MCLEAN, 2006; BHATTI, 2012).

\section{METODOLOGIA}

A presente pesquisa quanto à abordagem é qualitativa, pois segundo Minayo (2013), busca-se compreender em profundidade um fenômeno social em uma determinada realidade. Considerando os objetivos a serem atingidos, o estudo em questão, classifica-se como exploratório, pois busca fazer uma relação entre construtos não estudados de forma relacionada e descritiva, pois busca descrever como ocorrem os processos de inovação frugal.

A pesquisa de campo ocorreu em dois empreendimentos sociais que oferecem serviços financeiros para os moradores das comunidades onde atuam. Um está localizado na cidade de Fortaleza, a saber, o Banco Y e o outro na região metropolitana de Fortaleza no município de Maracanaú, o Banco X. A escolha desses empreendimentos ocorreu pelo fato de representarem dois contextos específicos de bancos comunitários que obtiveram êxito nos seus projetos sociais. Possuem uma abrangência considerável nos serviços e produtos que ofertam e se mostraram acessíveis a realização do estudo. O campo de estudo é classificado como institucional, pois conforme Pires (2008), o universo total analisado constitui o corpus empírico da pesquisa. 
Os dados foram coletados por meio de entrevistas que ocorreram nos meses de abril e maio de 2018 seguindo os procedimentos protocolares de pesquisa. Sendo apresentados e assinados no ato da entrevista os termos de confidencialidade e consentimento do uso das informações concedidas. Os sujeitos entrevistados foram colaboradores de diferentes cargos com o objetivo de diversificar as informações. A saber, Francisco (Diretor executivo do Banco X), Carolina (Coordenadora de projetos do Banco Y) e Luciana (Analista de crédito do Banco Y). Vale ressaltar que os nomes são fictícios conforme termo de confidencialidade.

Quanto a análise dos dados coletados, foi utilizada a técnica de análise de conteúdo. Segundo Bardin (1977), a análise de conteúdo ocorre por meio das fases de: a) pré-análise que consiste na organização do conteúdo, b) codificação onde ocorrem os registros dos dados, c) categorização que é a fase mais complexa onde são analisadas a frequência dos trechos, d) inferência e e) interpretação dos resultados.

\section{RESULTADOS E DISCUSSÃO}

Realizados os procedimentos de transcrição e categorização das entrevistas pode-se chegar a uma conclusão dos assuntos dominantes nas narrativas. Foram identificados quatro grandes temas: I) História, II) Propósito e objetivo, III) Inovação e inclusão social e IIII) Dificuldades.

\subsection{HISTÓRIA}

No tema história foi possível identificar através da fala dos entrevistados dois subtemas. O primeiro faz referência a história da organização e o contexto em que ela foi criada e o segundo refere-se à história de vida do entrevistado tendo em vista sua relação com a organização.

Do subtema emergiram dados históricos de quando e como surgiram as ideias de criar os empreendimentos sociais conforme relato abaixo:

Na verdade, a ideia do banco surgiu justamente por isso, porque nós somos um município muito rico, o distrito industrial, e nossa comunidade sempre foi muito pobre. Então isso incomodava, e a gente buscando um movimento social ligado ao movimento comunitário. Por isso, nós fundamos a associação de moradores antes de nós termos fundado o banco [...] (Francisco).

De acordo com Francisco a organização dos moradores em associações antecedeu o surgimento do banco $X$. Tendo em vista que a reunião em associação já possibilitava a discussão de muitas problemáticas referentes à realidade do bairro. Corroborando com a fala de Francisco, Carolina coloca que:

É o X, eu acho que depois de seminarista ele foi professor e depois trabalhou na diretoria do CSU (Centro Social Urbano) e foi aí então que ele começou a se envolver mais com a comunidade e a associação de moradores. E aí acho que, foi ele que realmente lançou a ideia de banco comunitário [...] (Carolina).

O que pode ser percebido é que os idealizadores dos dois bancos comunitários iniciaram suas atividades através da associação de moradores e posteriormente vislumbraram a necessidade de um banco comunitário. Uma segunda colocação é a história do entrevistado e a influência da organização na sua trajetória profissional. Carolina coloca que "a maioria dos funcionários começa ter outra visão de mundo, começa querer estudar". Essa visão ela desenvolveu devido a ter iniciado a sua graduação após começar a trabalhar no banco.

[...] Através do estudo ele vai me trazer outras qualificações e ampliar novos horizontes. E foi o que realmente aconteceu principalmente comigo. Então, eu acho que ele traz sim uma nova visão não só de sistema financeiro, mas das pessoas verem e acreditarem no potencial que a comunidade tem [...] (Carolina). 
Conforme a narrativa pode-se perceber de forma clara a influência da organização no que diz respeito a nova visão de mundo dos colaboradores, desde que começaram a fazer parte da organização impactando as perspectivas pessoais de cada um.

\title{
5.2 OBJETIVOS
}

Com base no relato dos entrevistados pode-se chegar ao tema: objetivos. Ele traz o propósito no qual os empreendimentos sociais foram criados, o porquê destes empreendimentos existirem. Nota-se que, o principal objetivo é à função social, segundo Francisco, "diminuir essa desigualdade e trazer mecanismo de inclusão das pessoas [...]".

Conforme colocado por Francisco, diminuir a desigualdade é o principal objetivo dos empreendimentos sociais. Essa desigualdade é gerada pelos fatores econômicos (FISCHER; COMINI, 2012) que deixam muitas pessoas à margem da sociedade com carência de muitas necessidades sociais básicas. Nesse sentido é que Tan, Williams e Tan (2005) colocam que o empreendedorismo social tem como objetivo atender os mais pobres.

Um segundo objetivo colocado pelos entrevistados, é que o banco comunitário foi criado devido às necessidades financeiras dos moradores dos bairros onde estão localizados. Neste sentido os entrevistados falaram que:

\begin{abstract}
Nós começamos com a finalidade de fazer microcrédito incluir as pessoas no sistema bancário, a gente acredita e tem pesquisa pra isso, que quando a gente acredita em pessoas que tem uma ideia de colocar um negócio, ela se desenvolve por si só com o trabalho. Então, foi através dessa tentativa que nós fundamos o banco [...] (Francisco).

A gente surgiu com a primeira ideia e o nosso primeiro projeto foi de realmente emprestar dinheiro para as pessoas. A gente começou a emprestar dinheiro para as pessoas para que as pessoas pudessem empreender. Essa primeira linha de crédito era só para pequenos empreendedores [...] (Carolina)
\end{abstract}

Corroborando com essa perspectiva Patrícia diz que, "O palmas também veio, para fazer empréstimos que beneficiasse a comunidade, criou a moeda palmas também que é outro benefício para a comunidade". Todas as narrativas consideram o serviço de microcrédito como fonte impulsionadora inicial dos serviços oferecidos pelo banco. A moeda palmas neste sentido, possibilitou que mais dinheiro circulasse dentro da comunidade através de uma moeda própria e que possui condições mais acessíveis para os moradores. Conforme considera Rodrigues (2015), o microcrédito tem uma fundamental importância para o desenvolvimento de pequenos empreendedores em diversas realidades.

O que pode ser percebido em todas as falas, é que a criação dos empreendimentos sociais foi com o objetivo de beneficiar a comunidade em suas necessidades financeiras básicas. Nesse mesmo sentido, é que Melo Neto e Froes (2002) enfatizam que, o empreendedorismo social é coletivo e traz benefícios em produtos e serviços para toda comunidade.

\subsection{INOVAÇÃO E INCLUSÃO SOCIAL}

Outro tema relevante que surgiu das narrativas foi inovação e inclusão social. Este diz respeito as considerações dos entrevistados sobre as inovações presentes nos empreendimentos, como subtema foi identificada a inovação frugal. A perspectiva de inovação presente nos empreendimentos sociais foi identificada nas falas abaixo dos entrevistados ao serem questionados se consideram o banco inovador.

Eu diria três grandes inovações [...] do ponto de vista econômico, poder atender uma mulher que tá no bolsa família, acreditar em uma mulher que tá no bolsa família com o microcrédito, com a capacitação para que ela possa se desenvolver e amanhã você perceber que ela não precisa mais do benefício social para sobreviver, por que ela conseguiu. Pessoas que estavam inadimplentes como nome no SPC e Serasa, mas são grandes profissionais e com a ajuda que a gente deu, com a oportunidade que a gente deu, ela hoje ser uma 
microempresária bem-sucedida. Então, é uma inovação muito grande. A outra inovação muito grande é do ponto de vista da autoestima [...] (Francisco).

Corroborando com a narrativa acima, Carolina coloca que considera o banco inovador "Em trazer cursos, fazer eventos, fazer projetos e estar envolvido politicamente em todo assunto que envolve o conjunto palmeiras, eu acho que ele é bem inovador nisso [...]". Por outro lado, Patrícia salienta que:

[...] O Y para mim, assim, vendo de fora muitas pessoas não reconhecem, mas o $\mathrm{Y}$ trouxe muitas inovações para a comunidade. Muitas! desde o início de quando eu nem era nascida, ele trazia cursos de costura, cursos de culinária, curso de TI para jovens e é tudo gratuito [...] (Patrícia)

Com relação à perspectiva das inovações em empreendimentos sociais conforme colocado pelos entrevistados, pode se inferir a função de inclusão social. Em todas as falas é evidente que os entrevistados consideram o Banco inovador devido a serviços tais como: cursos, oficinas, capacitação, oportunidade de empreender. Dessa forma, a inovação nos empreendimentos sociais está baseada em ações de inclusão social isso quer dizer, em oferecer serviços que as pessoas da comunidade não têm acesso ou não podem pagar por eles. Nessa perspectiva, Pervez, Maritz e Waal (2013) colocam a inovação como uma proposta socialmente responsável que é realizada por negócios sociais.

O subtema inovação frugal surgiu a partir do tema inovação. Nestes empreendimentos, foram identificadas algumas inovações consideradas frugais em produtos e serviços, conforme tabela abaixo:

\begin{tabular}{|c|c|c|}
\hline \multirow{4}{*}{ Banco X } & Inovações Frugais & Caracterização \\
\hline & É-dinheiro & $\begin{array}{c}\text { Aplicativo para transações } \\
\text { bancárias }\end{array}$ \\
\hline & Microcrédito & Empréstimos de baixo valor \\
\hline & Inclusão e Moradia & Casas de valor acessível \\
\hline \multirow{3}{*}{ Banco Y } & É-dinheiro & $\begin{array}{c}\text { Aplicativo para transações } \\
\text { bancárias }\end{array}$ \\
\hline & Microcrédito & Empréstimos valor acessível \\
\hline & Seguro de Vida & $\begin{array}{c}\text { Serviço de seguro de vida de valor } \\
\text { acessível }\end{array}$ \\
\hline
\end{tabular}

Fonte: Elaborado pelos Autores (2018)

Todas as inovações citadas acima possuem as características de redução substancial de custos, desempenho otimizado e concentra-se em funções básicas o que segundo Pisoni, Michelini e Marttignoni (2017) caracterizam as inovações frugais. Conforme pode ser observado, os dois empreendimentos ofertam praticamente os mesmos tipos de inovações frugais com exceção, do Banco Y que tem serviço de inclusão e moradia e o Banco $X$ que não possui o serviço de seguro de vida

Entendendo melhor as inovações frugais, o aplicativo funciona como uma conta bancária que é aberta de forma gratuita para os moradores do bairro que não têm acesso ao sistema bancário convencional. 
Possibilitando os moradores pagarem suas dívidas por meio do aplicativo e realizarem transações, Francisco considera que:

[...] ela pode vir aqui com conta de água, luz e telefone e pagar ali. Ela pode também, se quiser, ela própria, baixar e pagar do dela. E do aplicativo ela tem que vir aqui realizar a recarga aqui. Se ela vier aqui, ela pode colocar o valor que achar necessário é uma conta bancária no celular, você anda com ele no bolso, você paga, você transfere e compra nos supermercados credenciados (Francisco).

É importante ressaltar, que a comunidade em alguns aspectos pode ser classificada em como era antes e após as inovações frugais implementadas. Francisco coloca que antes os moradores da comunidade tinham que ir pagar suas dívidas de água, luz, telefone na CEASA (Centrais de Abastecimento do Ceará) que é consideravelmente distante do bairro e ainda tinham dispêndio com o deslocamento e a necessidade de pegar filas nos bancos convencionais, mas agora podem fazer através do aplicativo ou correspondente bancário. De modo semelhante, Carolina considera que, "A comunidade tinha que se deslocar para Messejana então, havia muita necessidade de um correspondente aqui dentro".

Nós temos hoje, um meio de pagamento que, pra você ter uma ideia a pessoa não tinha onde pagar suas contas, ou seja, ela teria que ir lá na CEASA. Então nós trouxemos o serviço, meio de pagamentos, hoje muito mais avançado [...] (Francisco).

Corroborando com essa afirmação, Carolina ainda coloca que: "eles diziam (os moradores) que o Conjunto Palmeiras era longe do centro da cidade de onde eles supriam suas necessidades de consumir, de se vestir e comprar. Comprar, tudo era no centro da cidade".

O microcrédito trouxe muitas transformações, pois fez com que os moradores pudessem empreender dentro do próprio bairro e assim circular mais recursos na comunidade gerando riqueza, investimentos e empregos. Para mais, Rodrigues et al. (2015) ressalta que o microcrédito é de fundamental importância para o pequeno empreendedor desempenhar suas atividades.

[...] Como é que a gente vai fazer com que essas pessoas queiram investir dentro do conjunto palmeiras elas mesmas. Investir que a gente fala, é abrir o seu próprio negócio. Já que eles trabalhavam como ambulantes lá fora, podiam trabalhar aqui dentro como comerciantes e empreendendo aqui dentro do conjunto Palmeiras. [...] A gente começou a emprestar dinheiro para as pessoas para que as pessoas pudessem empreender [...] (Carolina).

A oferta do microcrédito é realizada na forma de empréstimos de pequeno valor. As condições para adquirir o crédito são diferenciadas dos bancos convencionais que consultam restrição no CPF e necessitam de garantias. No banco comunitário as burocracias quase não existem, pois a avaliação é realizada pelos analistas de crédito e o dinheiro é liberado de forma rápida. Outra facilidade é a taxa de juros acessível à realidade dos tomadores do crédito.

[...] No microcrédito a taxa de juros é bem menor, a nossa avaliação é diferenciada e a gente não tem tanta burocracia para liberar o crédito. São as meninas que vão lá, visitam e olham e elas que dizem o valor, se vai ser liberado aquele valor que o cliente pediu ou não, mas na maioria das vezes é liberado. A forma de cobrança é diferente, porque a maioria das pessoas que trabalham dentro de um banco comunitário é da própria comunidade [...] (Carolina).

O serviço de inclusão de moradia que é ofertado pelo Banco $X$, são casas construídas em parceria com a Caixa Econômica Federal em que as condições de pagamento estão dentro da realidade dos consumidores de baixa renda e a documentação do morador é organizada pelo próprio banco comunitário.

[...] Paga mais quem ganha mais, então o que diferencia o minha casa, minha vida dos outros programas é o subsídio. Então, se eu não tenho renda eu não pago nada, se eu tenho uma 'rendazinha' diária eu pago proporcional [...] então, quem tem renda de R\$: 0,00 a R\$: 1800 é possível receber uma casa do governo com subsídio nesse caso, ele paga $10 \%$ da casa em 
média. Por exemplo, em Acopiara que a casa custa R\$: 70.000,00 ele paga R\$: 7.000,00 dividido em 10 anos. Aí vai ficar uma parcela que cabe no orçamento dele (Francisco).

Um serviço que não é tão conhecido como os outros é o do seguro de vida ofertado pelo Banco Y. Tem semelhanças com o seguro de vida convencional, a grande diferença é que ele é ofertado com um menor custo e condições de pagamento acessíveis, conforme considera Patrícia.

Ele, você paga uma vez por ano, certo? Tem um valor que você concorre no sorteio pela loteria federal por mês, e ele tem um valor que auxilia também no caso de morte e morte de um familiar. É um seguro de vida [...] (Patrícia).

\title{
5.4 DIFICULDADES
}

No que se refere às dificuldades foi possível identificar através das narrativas alguns problemas enfrentados pelos empreendimentos sociais em estudo. $O$ mais citado foi a falta de incentivos financeiros, Francisco coloca "[...] que a questão do financiamento mesmo, ou seja, o terceiro setor não tem linhas definidas de financiamento [...]". Confirmando o que diz Onozato e Teixeira (2013) que consideram que a maior dificuldade enfrentada pelos empreendimentos sociais é falta de recursos.

Outro aspecto que foi colocado em específico foi a falta de recursos para a linha de microcrédito que depende da liberação do banco. Francisco considera que "[...] com essa crise do governo e como nós não temos recursos próprios para microcrédito, então você depende sempre de recursos institucionais e com essa crise acabou todo mundo sendo prejudicado [...]". Ademais Patrícia coloca que:

[...] A gente não tem muito dinheiro para emprestar. A nossa maior dificuldade é essa, a gente queria ter mais dinheiro para emprestar a mais pessoas e a gente não tem. A carteira que os bancos comunitários têm junto ao BNDS é muito limitada. Essa é a angústia que os gerenciadores de um banco comunitário têm. Queria uma carteira maior, para poder emprestar mais dinheiro [...] (Patrícia).

Pelo menos duas dificuldades foram colocadas no que diz respeito ao uso do serviço aplicativo Édinheiro. A concorrência com os cartões de crédito e o uso do aplicativo no celular, devido algumas pessoas das comunidades não saberem manusear a ferramenta.

\begin{abstract}
A principal limitação do aplicativo agora é a concorrência com os cartões de crédito, a principal limitação é essa. O cartão de crédito ainda dá algumas possibilidades que o aplicativo não dá. Por exemplo, o cartão de crédito em qualquer lugar tem uma máquina que eu posso sacar dinheiro né? Aqui é só o Banco comunitário, e aí se o banco fechou às 6 horas da noite eu não posso mais sacar dinheiro por que o banco fechou [...] Um dos entraves que a gente encontrou foi por exemplo, quem compra mais no comércio são as donas de casa e quem sabe mexer menos também, são as dona de casa. Aí, quando a gente ia oferecer para as mulheres, elas alegavam não mexer (risos). Não, mas a gente fala: Não, mas é muito fácil, a gente lhe mostra [...] (Patrícia).
\end{abstract}

Conforme pode ser observado, são muitas dificuldades enfrentadas pelos empreendimentos sociais. No entanto, algumas delas são superadas com a criatividade. Conforme relata Patrícia, algumas donas de casa não querem aderir ao aplicativo devido ao fato de não saberem utilizar o celular, logo os funcionários do banco se disponibilizam a ensiná-las e acompanhá-las. Além disso, os benefícios que as inovações frugais trouxeram para as comunidades podem ser melhor percebidos quando se compara o antes e depois destes. 
Quadro 3 - Impactos das Inovações frugais nas comunidades

\begin{tabular}{|l|l|}
\hline \multicolumn{1}{|c|}{ Antes Não Havia } & \multicolumn{1}{c|}{ Depois } \\
\hline Acesso a crédito para empreender na comunidade & $\begin{array}{l}\text { Empreendimentos de moradores do próprio bairro } \\
\text { gerando renda e empregos através do microcrédito }\end{array}$ \\
\hline $\begin{array}{l}\text { Acesso a meio de pagamentos para as contas } \\
\text { convencionais: água, luz, telefone }\end{array}$ & Aplicativo para pagamento sem sair de casa \\
\hline Acesso à conta bancária para realizar transações & $\begin{array}{l}\text { Aplicativo que permite abertura de conta bancária } \\
\text { para depósitos e transferências }\end{array}$ \\
\hline $\begin{array}{l}\text { Pagamento no comércio do bairro somente através } \\
\text { de dinheiro em espécie }\end{array}$ & $\begin{array}{l}\text { Pagamento através de moeda comunitária por } \\
\text { aplicativo }\end{array}$ \\
\hline Programa de moradia popular & $\begin{array}{l}\text { Parceria com a Caixa Econômica Federal com } \\
\text { financiamentos acessíveis à realidade dos moradores }\end{array}$ \\
\hline Acesso a seguro de vida & $\begin{array}{l}\text { Seguro de vida de menor custo que cobre morte } \\
\text { pessoal e familiar }\end{array}$ \\
\hline
\end{tabular}

Fonte: Elaborado pelos Autores (2018)

\subsection{PROCESSO DE INOVAÇÃO FRUGAL}

Além dos quatro grandes temas achados, foi possível criar uma figura que ilustra de forma didática e sintética o processo em etapas da inovação frugal nos empreendimentos sociais estudados nesse trabalho. Conforme a Figura 1, o processo está composto em quatro etapas, a saber, identificação da oportunidade a ser explorada; análise da inovação para atender a demanda; implantação da inovação e controle.

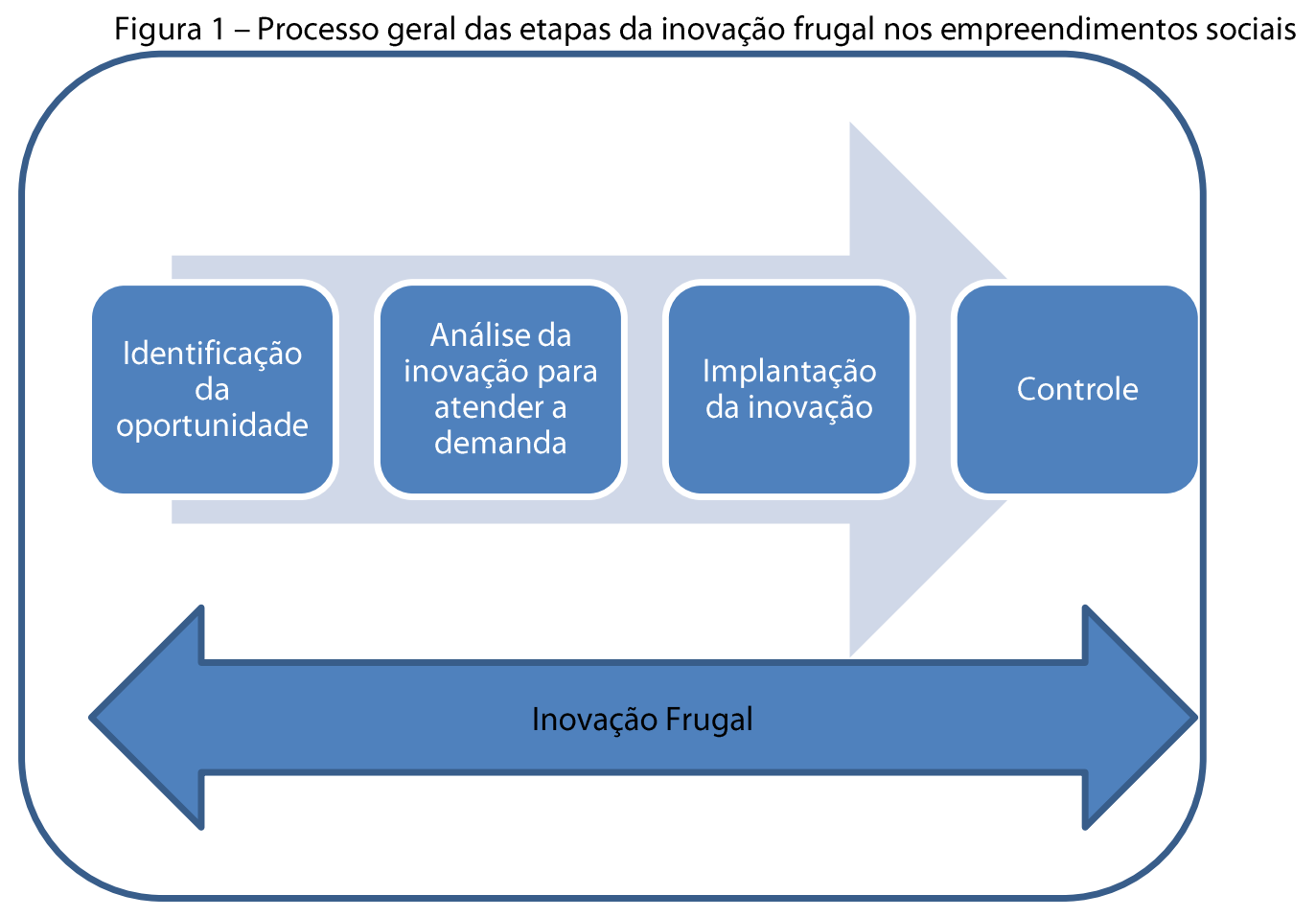

Fonte: Elaborado pelos autores baseados em Bardin (1977).

Nota-se que a inovação frugal está de forma transversal percorrendo todo o processo de ponta a ponta, tornando-se presente em todas as etapas de exploração da oportunidade pelo empreendimento. Isso demonstra, a necessidade de as inovações frugais serem pensadas e planejadas desde a sua concepção até a 
implantação, objetivando atender as necessidades específicas e mais emergentes das comunidades. $O$ que demonstra, que os empreendimentos sociais atendem com clareza este objetivo, pois são as instituições que têm como foco o coletivo em vez do individual visando sempre o impacto social.

\section{CONSIDERAÇÕES FINAIS}

O presente estudo teve como objetivo compreender o processo de inovação frugal em empreendimentos sociais de serviços financeiros. Os empreendimentos sociais estudados foram dois bancos comunitários na região metropolitana de Fortaleza que oferecem serviços financeiros para as comunidades onde estão inseridos. O estudo realizado revelou importantes aspectos das inovações frugais nestes empreendimentos.

Através da análise das entrevistas foram identificados quatro temas que foram norteadores para os resultados e discussões: histórico, propósito e objetivo, inovação e inclusão social, e dificuldades.

Foi observado que a perspectiva de inovação presente nos empreendimentos sociais está voltada para ações de inclusão social. Sendo que os entrevistados consideram que os empreendimentos em estudo são inovadores pelo de fato de criarem ações que integram as pessoas carentes da comunidade que normalmente são excluídas da sociedade e não tem acesso a cursos, linhas de crédito, serviços bancários.

Os produtos e serviços apresentados nas narrativas dos entrevistados deixam evidentes a presença de inovações frugais nos empreendimentos sociais estudados. Dessa forma, o que se pode concluir é que os produtos e serviços de microcrédito, É-dinheiro, inclusão de moradia e seguro de vida podem ser caracterizados como frugais devido atenderem aos critérios de concentração em funcionalidades básicas, redução substancial de custos e desempenho otimizado.

No que se refere ao processo de inovação frugal pode ser constatado que os produtos e serviços ofertados trouxeram grandes impactos nas comunidades onde estão inseridos. $O$ microcrédito favoreceu 0 desenvolvimento do bairro, sendo que antes deste ser ofertado a maioria das pessoas trabalhavam em áreas mais afastadas do bairro e a quantidade de comércios nessa localidade ainda era muita escassa, levando a população dessa região a se deslocar até o centro da cidade para utilizar esses negócios. Dessa forma, o bairro não possuía desenvolvimento econômico. Quanto ao aplicativo, muitas pessoas não tinham acesso a um sistema bancário e não podiam pagar boletos e realizar nenhum tipo de transação bancária. Nesse sentido, o aplicativo trouxe grandes mudanças, por permitir a compra através da moeda social e, como consequência, a geração de riqueza dentro da comunidade.

Algumas dificuldades enfrentadas pelos empreendimentos sociais foram apontadas por todos os entrevistados no que diz respeito aos aspectos de apoio financeiro e o uso de serviços. No aspecto financeiro a falta de recursos foi o principal fator, sendo que os empreendimentos sociais não possuem ajuda governamental. No uso dos serviços, foi colocado a dificuldade que alguns moradores do bairro possuem em utilizar o aplicativo É-dinheiro devido não saberem manusear o celular. No entanto, os funcionários do banco se disponibilizam a ensinar utilizar a ferramenta.

Dentre as limitações do estudo, pode-se considerar o fato dos resultados não serem generalizáveis devido à pesquisa ter sido realizada em empreendimentos sociais do segmento de serviços financeiros como também, o número de entrevistados ter sido limitado a três pessoas não permitindo uma maior diversidade na coleta de informações.

Finalmente, a importância do estudo se dá devido explorar como ocorrem as inovações frugais nos empreendimentos sociais, o que se configura como uma relação ainda não proposta na academia em outros estudos e reforça o importante papel que os empreendimentos sociais desempenham na sociedade como um fértil cenário para o surgimento de inovações.

Como sugestão de pesquisas futuras, indica-se estudos que abordem o processo de inovação frugal em empreendimentos sociais de outros segmentos e trabalhos que se proponham a criar modelos teóricos diversos do processo de inovação frugal em empreendimentos sociais. 


\section{REFERÊNCIAS}

ALTMANN, P.; ENGBERG, R. Frugal Innovation and Knowledge Transferability: Innovation for Emerging Markets Using Home-Based R\&D Western firms aiming to develop products for emerging markets may face knowledge transfer barriers that favor a home-based approach to frugal innovation. Research-Technology Management, v. 59, n. 1, p. 48-55, 2016.

ASHOKA. Empreendedorismo social e agentes de transformação social como forma de inclusão. Disponível em: http://www.ashoka.org.br. Acesso em: 28 jun. 2018.

BARDIN, L. Análise de conteúdo. Lisboa: Edições 70, 1977.

BRAGA, J. Motivações ao empreendedorismo social. Dissertação de Mestrado. 2013. 118 f. Dissertação (Mestrado em gestão de Serviços). Faculdade de Economia, Universidade do Porto, Portugal, 2013.

BHATTI, Y. A. What is frugal, what is innovation? Towards a theory of frugal innovation. Towards a Theory of Frugal Innovation (February 1, 2012), 2012.

BHATTI, Y. A.; VENTRESCA, M. How can 'frugal innovation'be conceptualized?. Available at SSRN 2203552, 2013.

BIANCHI, C. et al. Healthcare frugal innovation: a solving problem rationale under scarcity conditions. Technology in Society, v. 51, p. 74-80, 2017.

DACIN, M. T.; DACIN, P. A.; TRACEY, P. Social entrepreneurship: A critique and future directions. Organization science, v. 22, n. 5, p. 1203-1213, 2011.

FISCHER, R. M.; COMINI, G. Sustainable development: from responsibility to entrepreneurship. Revista de Administração (São Paulo), v. 47, n. 3, p. 363-369, 2012.

GENU, M. J.; MACHADO, L. C. R.; GÓMEZ, C. R. P.; PEREIRA, L. C. A. Identificação do processo de inovação social em empreendimentos sociais incubados. SEMINÁRIOS EM ADMINISTRAÇÃO, 20., 2017, São Paulo. Anais [...] São Paulo: SEMEAD, 2017.

HYYPIÄ, M; KHAN, R. Overcoming barriers to frugal innovation: Emerging opportunities for Finnish SMEs in Brazilian markets. Technology Innovation Management Review, v. 8, n. 4, p. 38-48, 2018.

LELIVELD, A.; KNORRINGA, P. Frugal Innovation and development research. The European Journal of Development Research, v.30, n 1, p. 1-16, 2017.

DE MELO NETO, F.P.; FROES, C. Empreendedorismo social: a transição para a sociedade sustentável. Qualitymark Editora Ltda, 2002.

MINAYO, M. C. S. O desafio do conhecimento. In: 0 desafio do conhecimento. 2011. p. 269-269.

MELKAS, H.; OIKARINEN, T.; PEKKARINEN, S. Understanding frugal innovation: a case study of university professionals in developed countries. Innovation and development, v. 9, n. 1, p. 25-40, 2019.

ONOZATO, E.; TEIXEIRA, R. M. Empreendedorismo social e a criação de uma organização do terceiro setor: 0 estudo de caso da Aliança Empreendedora. REDES: Revista do Desenvolvimento Regional, v. 18, n. 1, p. 4366, 2013.

OLIVEIRA, E. M. Empreendedorismo social no Brasil: atual configuração, perspectivas e desafios-notas introdutórias. Revista da FAE, v. 7, n. 2, 2004.

PEREDO, A.M; MCLEAN, M. Social entrepreneurship: A critical review of the concept. Journal of world business, v. 41, n. 1, p. 56-65, 2006. 
PRAHALAD, C. K. A riqueza na base da pirâmide. Bookman, Porto Alegre 2005.

PERVEZ, T.; MARITZ, A.; WAAL, A. Innovation and social entrepreneurship at the bottom of the pyramid conceptual framework. South African Journal of Economic and Management Sciences, v. 16, n. 5, p. 54-66, 2013.

PIRES, A. P. Amostragem e pesquisa qualitativa: ensaio teórico e metodológico. In: POUPART, J.; DESLAURIERS, J. P.; GROULX, L. H.; LAPIĖRRE, A.; ROBERT MAYER, R.; PIRES, A. A pesquisa qualitativa: enfoques epistemológicos e metodológicos. I tradução de Ana Cristina Nasser. - Petrópolis, Rio de Janeiro: Vozes, 2008

PISONI, A.; MICHELINI, L.; MARTIGNONI, G. Frugal approach to innovation: State of the art and future perspectives. Journal of Cleaner Production, v. 171, p. 107-126, 2017.

RADJOU, N.; PRABHU, J; AHUJA, S. Jugaad innovation: Think frugal, be flexible, generate breakthrough growth. John Wiley \& Sons, 2012.

ROSOLEN, T.; TISCOSKI, G. P.; COMINI, G. M. Empreendedorismo Social e Negócios Sociais: um estudo bibliométrico da publicação nacional e internacional. Revista interdisciplinar de gestão social, v. 3, n. 1, jan./abr., p. 85-105, 2014.

RODRIGUES, F. G.; XAVIER, J. N.; SOUSA, W. D.; NASCIMENTO, J. B.; BERNARDES, J. R. O microcrédito como ferramenta de desenvolvimento socioeconômico para os empreendedores e seus pequenos empreendimentos: um estudo de caso sobre o Crediamigo em Petrolina-PE. Revista Eletrônica Gestão \& Saúde, v. 1, n. 1, p. 1002-1026, 2015.

TAN, W. L.; WILLIAMS, J.; TAN, T.-M. Defining the 'Social' in 'Social Entrepreneurship: altruism and entrepreneurship. International Entrepreneurship and Management Journal, n. 1, p. 353-365, 2005.

VERGARA, S. C. Projetos e Relatórios de Pesquisa em Administração. 2ª ed. São Paulo: Atlas, 1998.

WINTERHALTER, S.; ZESCHKY, M. B.; NEUMANN, L.; GASSMMAN, O. Business Models for Frugal Innovation in Emerging Markets: The Case of the Medical Device and Laboratory Equipment Industry. Technovation, v. 66, p. 3-13, 2017. 